\title{
Determinants of Vertical Integration: Investment Efficiency, Product Differentiation and Firm Size
}

\author{
Toshiyuki Yamawake1, Shigetsune Yamoto², Hoe Chin Goi², Dong-Joon Lee ${ }^{3}$ \\ ${ }^{1}$ Faculty of Economics, Nagoya University of Commerce and Business, Aichi, Japan \\ ${ }^{2}$ Faculty of Management, Nagoya University of Commerce and Business, Aichi, Japan \\ ${ }^{3}$ Faculty of Commerce, Nagoya University of Commerce and Business, Aichi, Japan \\ Email: yamawake@nucba.ac.jp, yamoto@nucba.ac.jp, goi_hc@nucba.ac.jp,dongjoon@nucba.ac.jp
}

How to cite this paper: Yamawake, T., Yamoto, S., Goi, H.C. and Lee, D.-J. (2018) Determinants of Vertical Integration: Investment Efficiency, Product Differentiation and Firm Size. Theoretical Economics Letters, 8, 1028-1043. https://doi.org/10.4236/tel.2018.85071

Received: January 10, 2018

Accepted: April 14, 2018

Published: April 17, 2018

Copyright (c) 2018 by authors and Scientific Research Publishing Inc. This work is licensed under the Creative Commons Attribution International License (CC BY 4.0).

http://creativecommons.org/licenses/by/4.0/

Open Access

\begin{abstract}
This study examines the determinants of Merger and Acquisition (M \& A) when manufacturing firms integrate with retailing firms. We examine a manufacturing duopoly in which each upstream firm sells the output to its exclusive retailing firm. In sequence of the timing of game, the strategic variables are set as Research and Development (R \& D) investment, wholesale price by manufacturing firms and sales volume by retailing firms. The study concludes that degree of investment efficiency, product differentiation, and market size play important roles in vertical integration. Our conclusion shows that if product differentiation becomes greater, the vertical integration increases. Secondly, if the market size becomes larger, the vertical integration increases. Thirdly, the vertical integration increases when investment efficiency becomes higher. Our theoretical findings are also supported by the empirical results with the listed Japanese company data from 1996 to 2016.
\end{abstract}

\section{Keywords}

Investment Efficiency, Product Differentiation, Market Size, Vertical Integration

\section{Introduction}

The issue on the boundaries of firm has long been a discussed subject since originated by Coase $[1]^{1}$. Strategic behavior in successive oligopoly is an important area in industrial organization. Many literatures have focused on the boundaries

${ }^{1}$ For contributions at the early stage, see Williamson [2] [3], Grossman and Hart [4], and Hart and Moore [5]. 
of firm in a homogenous successive oligopoly ${ }^{2}$. However, there is a lack of studies that apply both theoretical and empirical analysis in vertical integration, which focuses on manufacturing and retailing firms. Thus, this paper examines the determinants of vertical integration in manufacturing and retailing industries. There is a growing trend of $M \&$ A cases among various industries in Japan over the past years. As an example, ASICS Holdings, a major sport manufacturing firm, integrated with ASICS Sales, a retailing firm, in 2015. Another example is that Tokyo Shirt, a retailing firm of men shirt, was taken over by Nisshinbo Textile, a manufacturing firm in textile industry, in 2015.

Theoretical analyses on whether firms integrate or separate have followed two streams. One stream focuses on a single channel. It is associated with the influence costs within firms and transaction costs across firms ${ }^{3}$. Based on the first stream, the amount of influence costs within firms and transaction costs across firms affect the make-or-buy decision in a single channel. Grossman and Hart [4], and Hart and Moore [5] focus on how asset ownership affects noncontractible specific investments by changing ex-post bargaining power. They explain that the ownership of assets is the instrument to shape the incentive for investment. The other stream focuses on the strategic behavior arising under channel competition ${ }^{4}$. Bonanno and Vickers [6], Bettignies [14], Rey and Stiglitz [15] explain that both firms choose to separate their downstream firms in order to mitigate the competition of the downstream market with franchise fees and no integration costs. Salinger [17] analyzes the effects of vertical integration on input and final markets when both vertically integrated and separated firms coexist. He shows that vertical integration may raise the costs of separated downstream firms. In addition, the higher wholesale price may or may not lead to higher retail price 5 . The empirical analyses follow two separate streams. One stream focuses on the determinants of $\mathrm{M} \& \mathrm{~A}$, such as financial synergies, market power, access to distribution channel, and entry into a new market. The other stream focuses on the effects of $M \& A$ on performance of firms. This paper follows the first stream by examining the important determinants of $M \& A$ when upstream firms integrate with downstream firms. There are closely related literatures relevant to this study. Hasbrouck [20], Andrade and Stafford [21], Danzon et al. [22] and Vyas et al. [23] use logistic regression to explain the motive to undertake M \& A. Hasbrouck [20], Andrade and Stafford [21], Danzon et al. [22], and Vyas et al. [23] adopt Tobin's Qas proxy for investment efficiency to analyze the motive of M \& A by logistic regression. Servaes [24] suggests that the higher the Tobin's $\mathrm{Q}$ is, the more the firm can create value by M \& A. Vyas et al. [23] and adopts

\footnotetext{
${ }^{2}$ See Bonanno and Vickers [6], Chen [7], Lin [8].

${ }^{3}$ See Grossman and Hart [4], Hart and Moore [5], Milgrom [9], Milgrom and Roberts [10] [11], Meyer et al. [12], Buchler and Schmutzler [13] and so on.

${ }^{4}$ See Bonanno and Vickers [6], Bettignies [14], Rey and Stiglitz [15], Gal-Or [16] and so on.

${ }^{5}$ Mcbride [18] provides the evidence that vertical integration in the cement and concrete industries lowers the cement prices. Another empirical analysis by Hortacsu and Syverson [19] supports the efficiency of vertical integration in the same industries.
} 
that advertising intensity as proxy for product differentiation to analyze the motive of M \& A by logistic regression. Danzon et al. [22], Vyas et al. [23], and Blonigen and Taylor [25] explain that the firm size of merger (or acquirer) is positively and significantly related to its $\mathrm{M} \& \mathrm{~A}$ decisions.

This study examines the determinants of $M \&$ A when manufacturing firms integrate with retailing firms. We examine a manufacturing duopoly in which each upstream firm sells the output to its exclusive retailing firm. In sequence of the timing of game, the strategic variables are set as $\mathrm{R} \& \mathrm{D}$ investment, wholesale price by manufacturing firms and sales volume by retailing firms. The study concludes that the degree of product differentiation, market size and investment efficiency are important determinants in integration. Our conclusion shows that if product differentiation become greater, the vertical integration increases. Secondly, if the market size becomes larger, the vertical integration increases. Thirdly, the integration increases when investment efficiency becomes higher. Our theoretical findings are also supported by the empirical results with the listed Japanese company data from 1996 to 2016.

Precious literature mainly deals with determinants of horizontal integration. There are few empirical analysis on vertical integration. Based on author's knowledge, there is no discussion of empirical analysis on vertical integrationin a manufacturing and retailing relationship. This paper examines the determinants of vertical integration that focuses on manufacturing and retailing industries. Therefore, the paper bridges the gap of the issue of vertical integration.

This paper is organized as follows. Section 2 sets up the model. Section 3 analyses the three sub-games and theoretical results. Section 4 estimates three hypotheses based on the theoretical results. Finally, section 5 makes the conclusion.

\section{The Model}

Consider a manufacturing duopoly in which each upstream firm sells its product to its exclusive downstream firm. The products are differentiated, and the degree of product differentiation is exogenous. The demand function is:

$$
p_{i}=a-q_{i}-d q_{j}, a>0 \text { and } d \in(0,1), i, j=1,2 ; i \neq j,
$$

where $p_{i}$ is the price and $q_{i}$ and $q_{j}$ are, respectively, the quantities for product $i$ and $j$. The parameter $d$ of the demand function measures the degree of product differentiation. As it approaches one, the products become less differentiated, and as it approaches zero, the products become more differentiated. The upstream firms initially possess the same constant marginal cost $c(<a)$ and identical $\mathrm{R} \& \mathrm{D}$ technologies. If each upstream firm engages in $\mathrm{R} \& \mathrm{D}$ investments activity, it can lower its marginal cost from $c$ to $c-x_{i}$ by spending $V\left(x_{i}\right)$ on $\mathrm{R} \& \mathrm{D}$ investments. It is common assumed that $\mathrm{R} \& \mathrm{D}$ investments are diminishing returns and that the R \& D cost function is quadratic. For simplicity, we assume that $V\left(x_{i}\right)=\frac{t x_{i}^{2}}{2}$, where the parameter $t>0$ represents the degree of $\mathrm{R} \& \mathrm{D}$ 
investments efficiency. For simplicity, one unit of the final product needs exactly one unit of the input and the cost of transforming the input into the final product is normalized to zero. For simplicity, we set the following assumption in order to guarantee that all possible variables are positive in equilibrium. Specifically, this assumption takes the following form:

$$
k\left(=\frac{c}{a}\right)>\frac{\left(8-d^{2}\right)[(2-d)(4+d) t-2]}{2 t\left[4\left(4-d^{2}\right)^{2} t-\left(16+8 d-4 d^{2}-d^{3}\right)\right]} .
$$

We posit a four-stage game. At stage 1, each upstream firm simultaneously chooses whether to integrate forward by acquiring its downstream firm at fixed costs F or not. At stage 2, each upstream firm simultaneously sets the R \& D investments level $\left(x_{i}, x_{j}\right)$. At stage 3 , if any upstream firms decide to separate its downstream firm, at stage 1 , they choose the wholesale prices $\left(w_{i}, w_{j}\right)$. Finally, at stage 4 , downstream firms compete a la Cournot fashion $\left(q_{i}, q_{j}\right)$ (Figure 1).

\section{Analysis}

In this section, we examine three sub-games: integration, separation, and asymmetric case. We solve a subgame perfect Nash equilibrium (SPNE) through backward induction.

\subsection{Integration}

We consider the case in which each upstream firm integrates its downstream firm. At stage 4, firm $i$ chooses the output $q_{p}$ so as to maximize its profit for given rival firm's output $q_{j}$ and $\mathrm{R} \& \mathrm{D}$ investments levels $\left(x_{i}, x_{j}\right)$. It's maximization problem is as follows:

$$
\max \Pi_{i}=\left(p_{i}-c_{i}\right) q_{i}-\frac{t x_{i}^{2}}{2}-F=\left(a-q_{i}-d q_{j}-c_{i}\right) q_{i}-\frac{t x_{i}^{2}}{2}-F, \text { w.r.t. } q_{i},
$$

where $\mathrm{F}$ is the costs of integration.

Differentiating the maximization problem with respect to $q_{i}$ and solving the two reaction functions, we obtain the equilibrium quantities $\left(q_{i}, q_{j}\right)$ as follows:

$$
q_{i}\left(c_{i}, c_{j}\right)=\frac{(2-d) a-2 c_{i}+d c_{j}}{4-d^{2}}, i, j=1,2 ; i \neq j .
$$

\begin{tabular}{cccc}
\hline & & & \\
\hline Stage 1 & Stage 2 & Stage 3 & Stage 4 \\
Upstream Firms & Upstream Firms & Upstream Firms & Downstream \\
Integration & Investments & Wholesale & Firms \\
$(V I)$ & $\left(x_{i}, x_{j}\right)$ & Prices $\left(w_{i}, w_{j}\right)$ & Outputs \\
or Separation & & & $\left(q_{i}, q_{j}\right)$
\end{tabular}

( VS)

Figure 1. Timing of the Game. 
At stage 2, firm $i$ chooses its $\mathrm{R} \& \mathrm{D}$ investments level $x_{i}$ so as to maximize its profit for a given rival firm's R \& D investments level $x_{j}$. It's maximization problem is as follows:

$$
\begin{aligned}
& \max \Pi_{i}\left(x_{i}, x_{j}\right)=\left(p_{i}-c_{i}\right) q_{i}-\frac{t x_{i}^{2}}{2}-F \\
& =\frac{\left[(2-d) a-2\left(c-x_{i}\right)+d\left(c-x_{j}\right)\right]^{2}}{\left(4-d^{2}\right)^{2}}-\frac{t x_{i}^{2}}{2}-F, \text { w.r.t. } x_{i}
\end{aligned}
$$

Differentiating the maximization problem with respect to $x_{i}$ and solving the two reaction functions, we obtain the equilibrium $\mathrm{R} \& \mathrm{D}$ investments levels $\left(x_{i}, x_{j}\right)$ as follows:

$$
x_{i}^{I I}=\frac{4(a-c)}{(2-d)(2+d)^{2} t-4},
$$

where the superscript "II" denotes the case that both upstream firms choose the integration. The first and second superscript, respectively, denote the channel selection chosen by upstream firm $i$ and $j$. Finally, we obtain the equilibrium quantities, prices, and profits as follows:

$$
\begin{gathered}
q_{i}^{I I}=q_{j}^{I I}=\frac{\left(4-d^{2}\right) t(a-c)}{(2-d)(2+d)^{2} t-4}, \\
p_{i}^{I I}=p_{j}^{I I}=c+\frac{\left(4-d^{2}\right) t-4}{(2-d)(2+d)^{2} t-4}, \\
\Pi_{i}^{I I}=\Pi_{j}^{I I}=\frac{\left[\left(4-d^{2}\right)^{2}-8\right] t(a-c)^{2}}{\left[(2-d)(2+d)^{2} t-4\right]^{2}}-F .
\end{gathered}
$$

\subsection{Separation}

We examine the case in which each upstream firm sells its product to its own downstream firm. At stage 4, downstream firm $i$ sets its quantities $q_{i}$ so as to maximize its profits for given rival's quantities $q_{p}$, wholesale prices $\left(w_{i}, w_{j}\right)$, and $\mathrm{R} \& \mathrm{D}$ investments levels $\left(x_{i}, x_{j}\right)$. Its maximization problem is as follows:

$$
\max \pi_{i}=\left(p_{i}-w_{i}\right) q_{i}=\left(a-q_{i}-d q_{j}-w_{i}\right) q_{i} \text {, w.r.t. } q_{i} \text {. }
$$

Differentiating the maximization problem with respect to $q_{i}$ and solving the two reaction functions, we obtain the equilibrium quantities $\left(q_{i}, q_{j}\right)$ as follows:

$$
q_{i}\left(w_{i}, w_{j}\right)=\frac{(2-d) a-2 w_{i}+d w_{j}}{4-d^{2}}, i, j=1,2 ; i \neq j .
$$

At stage 3, upstream firm $i$ chooses the wholesale price $w_{i}$ so as to maximize its profits for given rival's wholesale price $w_{j}$ and $\mathrm{R} \& \mathrm{D}$ investments levels $\left(x_{i}, x_{j}\right)$. Therefore, its maximization problem is as follows:

$$
\max \Pi_{i}=\left(w_{i}-c_{i}\right) q_{i}-\frac{t x_{i}^{2}}{2}, \text { w.r.t. } w_{i} .
$$


Differentiating the maximization problem with respect to $w_{j}$ and solving the two reaction functions, we obtain the equilibrium wholesale prices $\left(w_{i}, w_{j}\right)$ as follows:

$$
w_{i}\left(c_{i}, c_{j}\right)=\frac{(4+d)(2-d) a+8 c_{i}+2 d c_{j}}{(4+d)(4-d)}, i, j=1,2 ; i \neq j .
$$

At stage 2, upstream firm $i$ chooses the R \& D investment levels $X_{i}$, so as to maximize its profits for a given rival's R \& D investment levels $X_{j}$ as follows:

$$
\max \Pi_{i}\left(x_{i}, x_{j}\right)=\left(w_{i}-c+x_{i}\right) q_{i}-\frac{t x_{i}^{2}}{2}, \text { w.r.t. } x_{i} .
$$

Differentiating the maximization problem with respect to $x_{i}$ and solving the two reaction functions, we obtain the equilibrium $\mathrm{R} \& \mathrm{D}$ investments levels as follows:

$$
x_{i}^{S S}=\frac{4(8-d)^{2}(a-c)}{(2+d)(4+d)(4-d)^{2} t-4\left(8-d^{2}\right)},
$$

where the superscript "SS" denotes the case that each upstream firm separates its downstream firm. The first and second superscript, respectively, denote the channel selection chosen by upstream firm $i$ and $j$.

Finally, the equilibrium wholesale prices, quantities, prices, downstream and upstream firm's profits are as follows:

$$
\begin{gathered}
w_{i}^{S S}=w_{j}^{S S}=c+\frac{\left[\left(64-16 d^{2}+d^{4}\right) t-4\left(8-d^{2}\right)\right](a-c)}{(2+d)(4+d)(4-d)^{2} t-4\left(8-d^{2}\right)}, \\
q_{i}^{S S}=q_{j}^{S S}=\frac{\left[2\left(16-d^{2}\right) t\right](a-c)}{(2+d)(4+d)(4-d)^{2} t-4\left(8-d^{2}\right)}, \\
p_{i}^{S S}=p_{j}^{S S}=c+\frac{\left[\left(96-22 d^{2}+d^{4}\right) t-4\left(8-d^{2}\right)\right](a-c)}{(2+d)(4+d)(4-d)^{2} t-4\left(8-d^{2}\right)}, \\
\Pi_{i}^{S S}=\Pi_{j}^{S S}=\frac{2 t\left[\left(4-d^{2}\right)\left(16-d^{2}\right)^{2} t-4\left(8-d^{2}\right)^{2}\right](a-c)^{2}}{\left[(2+d)(4+d)(4-d)^{2} t-4\left(8-d^{2}\right)\right]^{2}} .
\end{gathered}
$$

Firstly, we focus on R \& D investment levels under vertical integration and separation. Comparing Equation (4-1) and Equation (7-1), we obtain the following results:

$$
x_{i}^{I I}-x_{i}^{S S}=\frac{4\left(64+10 d^{3}-d^{4}-d^{5}\right)(a-c)}{\left[(2-d)(2+d)^{2} t-4\right]\left[(2+d)(4+d)(4-d)^{2} t-4\left(8-d^{2}\right)\right]}>0 .
$$

Therefore, we summarize the result in Lemma 1.

Lemma 1 Under Equation (2-1) and Equation (2-2), R \& D investments levels are larger under vertical integration than under vertical separation.

Secondly, we focus on upstream firms' profits under vertical integration and 
separation. Comparing Equation (4-4) and Equation (7-5), we obtain the following results:

$$
\begin{aligned}
& \Pi_{i}^{I I}>=<\Pi_{i}^{S S} \\
& \Leftrightarrow \frac{F}{(a-c)^{2}}<=>t\left[\frac{\left(4-d^{2}\right)^{2} t-8}{\left\{(2-d)(2+d)^{2} t-4\right\}^{2}}\right. \\
& \left.-\frac{(4-d)\left(16-d^{2}\right)^{2} t-4\left(8-d^{2}\right)^{2}}{\left\{(4+d)(2+d)(4-d)^{2} t-4\left(8-d^{2}\right)\right\}^{2}}\right] \equiv F^{*} .
\end{aligned}
$$

Therefore, we summarize the results in Lemma 2.

Lemma 2 Under Equation (2-1) and Equation (2-2), when $\frac{F}{(a-c)^{2}} \leq F^{*}$, the upstream firms' profits are larger under vertical integration than under vertical separation.

The intuition behind Lemma 2 can be explained as follows. Vertical integration has the advantage of eliminating double margin distortion, but has the disadvantage of paying integration costs. On the other hand, vertical separation has the advantage of no integration costs, but has the disadvantage of double margin distortion. Equation (9) has two implications. Firstly, $F$ is decreasing in $d$. It implies that when $d$ approaches 0 , double margin distortion becomes greater. Therefore, each upstream firm has to pay a larger integration costs when both products are more differentiated. Secondly, the denominator of the left-hand side, $(a-c)^{2}$ implies the market size. The larger the market size is, the higher integration costs upstream firms pay. In other words, when the market size becomes larger, each upstream firm is liable to integrate its downstream firm.

Next, we focus on the relationship between upstream firms' profits and product differentiation. Differentiating Equation (4-4) with respect to $d$, we obtain the following results:

$$
\frac{\partial \Pi^{I I}}{\partial d}=-\frac{2(a-c)^{2} t^{2}\left[\left(4-d^{3}\right)^{3} t-8(1-d)(2+d)^{2}\right]}{\left[(2-d)(2+d)^{2} t-4\right]^{3}}<0 .
$$

Therefore, we summarize the results in Lemma 3.

Lemma 3 Under Equation (2-1) and Equation (2-2), the upstream firms' profits under vertical integration are larger when both products are more differentiated.

We also focus on the relationship between upstream firms' profits and investment efficiency. Differentiating Equation (4-4) with respect to $t$, we obtain the following results:

$$
\frac{\partial \Pi^{I I}}{\partial t}=-\frac{8(a-c)^{2}\left[(2-d)(1-d)(2+d)^{2} t-4\right]}{\left[(2-d)(2+d)^{2} t-4\right]^{3}}<0 .
$$


Therefore, we summarize the results in Lemma 4.

Lemma 4 Under Equation (2-1) and Equation (2-2), the upstream firms will adopt the integration when investment efficiency is higher.

\subsection{Asymmetry}

Finally, we turn to the asymmetric case in which upstream firm i integrates its downstream firm, while upstream firm $j$ sells its product through its exclusive downstream firm. At stage 4, integrated firm $i$ chooses its output so as to maximize its profits, while downstream firm $j$ sets its output so as to maximize its profits. The maximization problems are, respectively, given as follows:

$$
\begin{gathered}
\max \Pi_{i}=\left(p_{i}-c_{i}\right) q_{i}-\frac{t x_{i}^{2}}{2}-F=\left(a-q_{i}-d q_{j}-c_{i}\right) q_{i}-\frac{t x_{i}^{2}}{2}-F, \text { w.r.t. } q_{i}, \\
\max \pi_{j}=\left(p_{j}-w_{j}\right) q_{j}=\left(a-q_{j}-d q_{i}-w_{j}\right) q_{j}, \text { w.r.t. } q_{j} .
\end{gathered}
$$

Note that the marginal costs of integrated firm $i$ and downstream firm $j$ are, respectively, $c_{i}$ and $w_{j}$

Differentiating the maximization problems with respect to $q_{i}$ and $q_{j}$ and solving the two reaction functions, we obtain the equilibrium quantities as follows:

$$
\begin{aligned}
& q_{i}\left(c_{i}, w_{j}\right)=\frac{(2-d) a-2 c_{i}+d w_{j}}{4-d^{2}}, \\
& q_{j}\left(c_{i}, w_{j}\right)=\frac{(2-d) a+d c_{i}-2 w_{j}}{4-d^{2}} .
\end{aligned}
$$

At stage 3, upstream firm $j$ chooses the wholesale price $w_{j}$ in order to maximize its profits. Its maximization problem is as follows:

$$
\max \Pi_{j}=\left(w_{j}-c_{j}\right) q_{j}-\frac{t x_{j}^{2}}{2}, \text { w.r.t. } w_{j} .
$$

From the F. O. C., we obtain the equilibrium wholesale price as follows:

$$
w_{j}\left(c_{i}, c_{j}\right)=\frac{(2-d) a+d c_{i}+2 c_{j}}{4} .
$$

At stage 2, integrated firm i sets the R \& D investment levels $X_{i}$ so as to maximize its profits for given rival's $\mathrm{R} \& \mathrm{D}$ investment levels $X_{j}$ Its maximization problem is as follows:

$$
\begin{aligned}
\max \Pi_{i}= & \left(p_{i}-c_{i}\right) q_{i}-\frac{t x_{i}^{2}}{2}-F \\
= & \frac{\left[(2-d)(4+d) a-\left(8-d^{2}\right) c_{i}+2 d c_{j}\right]^{2}}{\left[4\left(4-d^{2}\right)\right]^{2}} \\
& -\frac{t x_{i}^{2}}{2}-F, \text { w.r.t. } x_{i} .
\end{aligned}
$$

On the other hand, upstream firm $j$ sets the R \& D investment levels $x_{j}$ so as to maximize its profits for given rival's $\mathrm{R} \& \mathrm{D}$ investment levels $X_{i}$. Its maximization problem is as follows: 


$$
\begin{aligned}
\max \Pi_{j} & =\left(w_{j}-c_{j}\right) q_{j}-\frac{t x_{j}^{2}}{2} \\
& =\frac{\left[(2-d) a+d c_{i}-2 c_{j}\right]^{2}}{8\left(4-d^{2}\right)}-\frac{t x_{j}^{2}}{2}, \text { w.r.t. } w_{j} .
\end{aligned}
$$

Solving the two reaction functions, we obtain the equilibrium R \& D investment levels as follows:

$$
\begin{aligned}
& x_{i}^{A I}=\frac{\left(8-d^{2}\right)[(2-d)(4+d) t-2](a-c)}{8\left(4-d^{2}\right)^{2} t^{2}-\left(96-24 d^{2}+d^{4}\right) t+2\left(8-d^{2}\right)}, \\
& x_{j}^{A S}=\frac{2\left[(2+d)(2-d)^{2} t-\left(8-d^{2}\right)\right](a-c)}{8\left(4-d^{2}\right)^{2} t^{2}-\left(96-24 d^{2}+d^{4}\right) t+2\left(8-d^{2}\right)},
\end{aligned}
$$

where the superscript "AI" and "AS", respectively, denote asymmetric integration and separation. Finally, we obtain the equilibrium wholesale price, quantities, prices, and downstream and upstream firms' profits as follows:

$$
\begin{gathered}
w^{A S}=c+\frac{\left[\left(4-d^{2}\right) t-2\right]\left[2(2+d)(2-d)^{2} t-\left(8-d^{2}\right)\right](a-c)}{\Delta}, \\
q_{i}^{A I}=\frac{\left[2\left(4-d^{2}\right) t\right][(4+d)(2-d) t-2](a-c)}{\Delta}, \\
q_{j}^{A S}=\frac{2 t\left[2(2+d)(2-d)^{2} t-\left(8-d^{2}\right)\right](a-c)}{\Delta}, \\
p_{i}^{A I}=c+\frac{[(2-d)(4+d) t-2]\left[2\left(4-d^{2}\right) t-\left(8-d^{2}\right)\right](a-c)}{\Delta}, \\
p_{j}^{A S}=c+\frac{\left[\left(6-d^{2}\right) t-2\right]\left[2(2+d)(2-d)^{2} t-\left(8-d^{2}\right)\right](a-c)}{\Delta}, \\
\Pi_{i}^{A I}=\frac{\pi_{j}^{A S}=\frac{4 t^{2}\left[2(2+d)(2-d)^{2} t-\left(8-d^{2}\right)\right]^{2}(a-c)^{2}}{\Delta^{2}}}{\left.2\left(4-d^{2}\right)^{2} t-8\left(8-d^{2}\right)^{2}\right][(2-d)(4+d) t-2]^{2}(a-c)^{2}} \\
\prod_{j}^{A S}=\frac{2 t\left[\left(4-d^{2}\right) t-1\right]\left[2(2+d)(2-d)^{2} t-\left(8-d^{2}\right)\right]^{2}(a-c)^{2}}{\Delta^{2}},
\end{gathered}
$$

where $\Delta=8\left(4-d^{2}\right)^{2} t^{2}-\left(96-24 d^{2}+d^{4}\right) t+2\left(8-d^{2}\right)$.

\subsection{Equilibrium Market Structure}

In the previous sub-sections, we analyze three cases: integration, separation, and asymmetric case. In this section, we examine the decision on integration or separation by each upstream firm. Our main result is characterized in Proposition 1 . 
Proposition 1: Under Equation (2-1) and Equation (2-2), we conclude the results as follows:

1) The integration occurs if the profits under integration exceed those of separated firm under asymmetric case $\left(0 \leq \Pi^{I I}-\Pi^{A S}\right)$.

2) The separation occurs if the costs of integration exceed the benefits for a firm that faces a separated firm $\left(\Pi^{A I}-\Pi^{S S} \leq 0\right)$.

3) The asymmetric case occurs if the costs of integration exist between the benefits of a firm that faces an integrated firm and the benefits of a firm that faces a separated firm $\left(\Pi^{A I}-\Pi^{S S} \leq 0\right.$ and $\left.0 \leq \Pi^{I I}-\Pi^{A S}\right)$.

We show a simple graphical explanation for Proposition 1. Figure 2 depicts the various types of equilibrium market structures as a function of product differentiation $d$ and the costs of integration $F$, fixing the market size at $(a-c)^{2}=1$ and the efficiency parameter of investment $t=2$. If the integration costs are sufficiently small, both upstream firms integrate with the downstream firms.

Figure 3 also illustrates the various types of equilibrium market structures as a

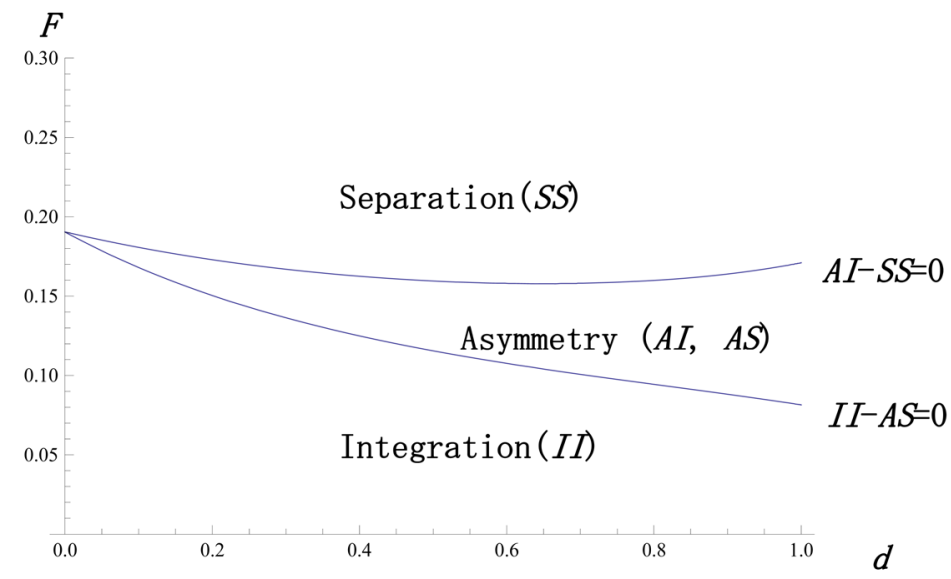

Figure 2. Equilibrium Market Structure 1 (when $(a-c)^{2}=1$ and $t=2$ ).

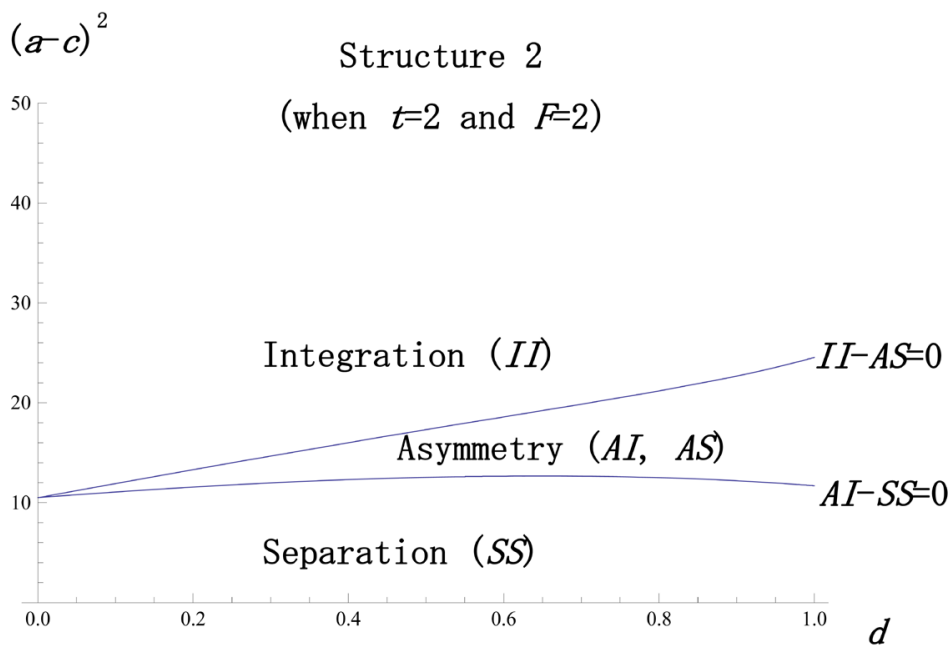

Figure 3. Equilibrium Market Structure 2 (when $t=2$ and $F=2$ ). 
function of product differentiation $\mathrm{d}$ and the market size $\alpha=(a-c)^{2}$, fixing the efficiency parameter of $\mathrm{R} \& \mathrm{D}$ investments $t=2$ and the costs of integration $F=2$. Figure 3 indicates that when both products become more differentiated, both upstream firms will integrate with the downstream firms. Next, we consider the relationship between market size $\alpha$ and the degree of product differentiation d from Figure 3. Figure 3 implies that when the market size becomes larger, both upstream firms will integrate with the downstream firms. Therefore, we summarize the results in Lemma 4 and Lemma 5 as follows:

Lemma 5 Under Equation (2-1) and Equation (2-2), if product differentiation become greater, the vertical integration increases.

Lemma 6 Under Equation (2-1) and Equation (2-2), if the market size becomes larger, the vertical integration increases.

\section{Empirical Analysis}

In this section, we conduct empirical analysis with $\mathrm{M} \& \mathrm{~A}$ and financial data to test the theoretical results based on Lemma 4, 5 and 6 . We propose three hypotheses as follows:

H1: When investment efficiency becomes higher, the more likely upstream firms will adopt vertical integration.

$\mathrm{H} 2$ : When product differentiation become greater, the more likely upstream firms will adopt vertical integration.

H3: When the market size becomes larger, the more likely upstream firms will adopt vertical integration.

\subsection{Data Collection}

In our empirical analysis, we use the data about vertical integration by upstream firm in Japan from 1996 to 2016. The data source is obtained from RECOF's M \& A database. RECOF collects M \& A data by interviewing companies based on news releases, newspapers and magazines in Japan. The definition of the merger in RECOF's $M$ \& A database is that two or more companies will become one company in a merger agreement and the definition of the acquisition in RECOF's M \& A database is to acquire more than $50 \%$ of the shares. We also organize the financial data of upstream firms for the period from 1995 to $2015^{6}$ by using Nikkei NEEDS DVD and EOL online database ${ }^{7}$. RECOF's M \& A database includes horizontal and vertical integration data and so on. We collect the vertical integration data. Among the vertical integration data, we use the data made up of upstream firms in manufacturing industry, and downstream firm in wholesale or retail industry, from RECOF's M \& A database ${ }^{8}$. We use industry

${ }^{6}$ The reason of the data acquisition period being deviated by one year is that independent variables of our logistic regression lag one year to the dependent variable.

${ }^{7}$ Both databases obtain financial data from corporate financial statements.

${ }^{8}$ Manufacturing industry consists of foods, textiles \& apparels, pulp \& paper, chemicals, pharmaceutical, oil \& coal products, rubber products, glass \& ceramics products, iron \& steel, nonferrous metals, metal products, machinery, electric appliances, transportation equipment, precision instruments, and other industry. 
classification based on the TOPIX Sector Indices of Tokyo Stock Exchange. The number of M \& As among Japanese firms from 1996 to 2016 is 24,354. From 1996 to 2016, the number of vertical integration cases is 641 and the number of upstream firms which merge with (or acquire) downstream firms is 433.

\subsection{Estimation Model}

We test the three hypotheses by logistic regression. The reason to use logistic regression is for a firm to select vertical integration or separation. Andrade and Stafford [21], Danzon et al. [22] and Vyas et al. [23] use logistic regression to explain the motive to undertake $\mathrm{M} \& \mathrm{~A}$. The dependent variable $\mathrm{z}$ is a set of dummy variables for vertical integration. From 1996 to 2016, we check whether each upstream firm undertakes vertical integration or not. If the firm undertakes vertical integration in each year, we assign 1 to dummy variable, and otherwise 0 to dummy variable ${ }^{9}$. The set of all the dummy variables is the dependent variable $z$.

To verify hypothesis H1, we adopt Tobin's Q (TQ) as proxy for firm's investment efficiency. Hasbrouck [20], Andrade and Stafford [21], Danzon et al. [22], and Vyas et al. [23] also apply TQ as proxy for investment efficiency to analyze the motive of $\mathrm{M} \& \mathrm{~A}$ by logistic regression. Following the previous literature, we also test whether TQ is positively related to $\mathrm{M} \& \mathrm{~A}$ strategy or not by logistic regression.

To verify hypothesis $\mathrm{H} 2$, we consider advertising intensity (ADV) as proxy for product differentiation. ADV is defined as ratio of advertisement expenses to the net sales of the firm. Some theoretical literatures, such as Bain [26], Comanor and Wilson [27], argue that advertisements influence consumer preferences. Thus, they claim that advertisement is a main factor of product differentiation. Moreover, some empirical literatures, such as Vernon and Nourse [28], Porter [29], conduct analyses to confirm the theory indicated by Bain [26]. In their empirical analyses, ADV is used as an indicator to measure product differentiation. Vyas et al. [23] also adopts ADV as proxy for product differentiation to analyze the motive of $M \& A$ by logistic regression.

To verify hypothesis H3, we adopt firm size as proxy for market size. Based on our theoretical model, firm size is half of market size. We estimate that integration is an increasing function in firm size. Danzon et al. [22], Vyas et al. [23], and Blonigen and Taylor [25] explain that the firm size of merger (or acquirer) is positively and significantly related to its $M \& A$ decisions. We adopt natural log of the net sales (NLS) as proxy for the firm's size following Vyas et al. [23] ${ }^{10}$.

We briefly explain the estimation model. Each independent variable lags one year to the dummy variable of the year in order to avoid simultaneous bias problem ${ }^{11,12}$. We exclude the data of independent variables that are not ${ }^{9}$ For example, if upstream firms undertake vertical integration in the year of 2000 , the dummy variable of the year of 2000 is 1 . Otherwise, the dummy variable is zero.

${ }^{10}$ For example, Danzon et al. [22] and Blonigen and Taylor [25], respectively, adopt natural log of the total assets and natural log of the enterprise value.

${ }^{11}$ Dependent variable uses the data in 2016, but independent variables uses financial data in 2015.

${ }^{12}$ For example, advertisement intensity, net sales, and Tobin's Qmay be high (or low) due to integration. 
available $^{13}$. The number of sample data is 28,290 and the number of integration is 413 . We introduce year dummy and industry dummy variable to eliminate the effect on integration ${ }^{14}$.

Table 1 describes the variables and their definitions. Table 2 depicts the mean, median, minimum, maximum, and standard deviation of the variables that are not dummy variables for the sample data. Table 3 lists the correlation matrix for the variables that are not dummy variables to check the dependency among the variables. In Table 3, as the coefficient of the correlation between variables are not large, the variables are appropriate.

We set the empirical model as follows:

$$
z=\alpha+\beta T Q+\gamma A D V+\delta L N S+\epsilon Y D+\zeta I D
$$

Table 1. Definition of Variables.

\begin{tabular}{ccc}
\hline Variable & Symbol & Definition of the Variable \\
\hline $\begin{array}{c}\text { Integration dummy } \\
\text { (dependent variable })\end{array}$ & $\mathrm{z}$ & $\begin{array}{c}\text { Dummy }=1 \text { for firms undertaking vertical } \\
\text { integration, } 0 \text { otherwise }\end{array}$ \\
Tobin's $\mathrm{Q}$ & TQ & $\begin{array}{c}\text { Ratio of firm value to total assets } \\
\text { Advertising intensity }\end{array}$ \\
Net sales & ADV & Ratio of advertisement expense to net sales \\
Year dummy & YD & $\begin{array}{c}\text { Natural log of netsales } \\
\text { of year dummy, otherwise Dummy }=0\end{array}$ \\
Industry dummy & ID & $\begin{array}{c}\text { Dummy }=1 \text { when the industry of } \mathrm{z} \text { is same as the } \\
\text { industry of industry dummy, otherwise Dummy }=0\end{array}$
\end{tabular}

Notes: YD is a vector which corresponds to each year from 1997 to 2016 . If the row of the year in the YD corresponds to year of $z$, the row is 1 , otherwise is 0 . ID is a vector which corresponds to each industry. If the row of the industry in the ID corresponds to industry of $\mathrm{z}$, the row is 1 , otherwise is 0 .

Table 2. Summary Statistics.

\begin{tabular}{cccccc}
\hline & Mean & Median & Min & Max & Std. Dev. \\
\hline TQ & 1.182 & 1.032 & 0.182 & 45.141 & 0.794 \\
ADV & 1.107 & 0.318 & 0.001 & 152.778 & 2.757 \\
LNS & 24.196 & 24.047 & 17.399 & 30.400 & 1.471 \\
\hline
\end{tabular}

Table 3. Correlation Matrix.

\begin{tabular}{cccc}
\hline & TQ & ADV & LNS \\
\hline TQ & 1 & & \\
ADV & 0.107 & 1 & \\
LNS & 0.049 & -0.033 & 1 \\
\hline
\end{tabular}

${ }^{13}$ The financial data are mainly advertising expenses. According to Japanese financial rule, firms do not need to report their advertising expenses if the amount is lower than $10 \%$ of selling and administration cost.

${ }^{14}$ In order to distinguish industry of upstream firms, we used industry dummy based on TOPIX Sector Indices. 
where $\alpha, \beta, \gamma, \delta, \epsilon, \zeta$ are parameters.

\subsection{Regression Results}

In subsection 4.3, we show the results of the logistic regression. Table 4 shows that the coefficient of TQ is positive and significant at the $1 \%$ level. We conclude that the integration increases when investment efficiency is higher. The results support hypothesis H1. The coefficient of ADV is positive and significant at the $1 \%$ level. Therefore, we conclude that when products are more differentiated, the upstream firms will adopt integration. The results support hypothesis H2.The coefficient of LNS is positive and statistically significant at the $1 \%$ level. We conclude that market size is larger, the upstream firms will adopt integration. The results support hypothesis $\mathrm{H} 3$.

In Table 4, observation is the number of sample data. We use Wald and Likelihood-ratio test to check whether all coefficients are significant or not. Based on results of Wald test, p-value is less than 0.01 . The null hypothesis is rejected. The result of Likelihood-ratio is also significant at the $1 \%$ level. It implies that our logistic model is clearly supported.

\section{Conclusions}

This paper examines the relationship between vertical integration and three determinants: product differentiation, market size and investment efficiency. There are three important findings. Firstly, if product differentiation becomes greater, the vertical integration increases. Secondly, if the market size becomes larger, the vertical integration increases. Thirdly, the vertical integration increases when investment efficiency becomes higher. We also estimate the hypotheses, $\mathrm{H} 1, \mathrm{H} 2$, and H3, based on the analytical model. For this purpose, we collect data of vertical integration and financial data of Japanese firms from 1996 to 2016. We investigate how $\mathrm{ADV}, \mathrm{TQ}$, and LNS have impacted on decisions of upstream firms

Table 4. Results of logistic regression.

\begin{tabular}{cc}
\hline TQ & $0.099^{* * *}$ \\
ADV & $(7.722)$ \\
& $0.042^{* * *}$ \\
LNS & $(18.891)$ \\
& $0.291^{* * *}$ \\
Constant & $(76.458)$ \\
Year Dummy & $-14.477^{* * *}$ \\
Industry Dummy & $(231.745)$ \\
Observations & Yes \\
Wald & 28,290 \\
Likelihood-ratio & $246.919^{* * *}$ \\
\hline
\end{tabular}

Notes: Statistical significance at the $1 \%$ level is denoted by ${ }^{* * *}$. Values in the parentheses are wald-statistics for coefficient estimates. 
to undertake vertical integration using logistic regression. Our findings show that the coefficients of ADV, TQ, and LNS are positive and statistically significant. These results support $\mathrm{H} 1, \mathrm{H} 2$, and $\mathrm{H} 3$. Thus, we conclude that the theoretical model is supported by empirical analysis.

In this paper, under the assumptions of linear demand and constant marginal cost, we show that firms' strategic choices depend only on product differentiation, market size, and investment efficiency. In the general case, under quadratic cost function and non-linear demand, one would raise the query if these determinants could also play important roles in vertical integration. The empirical analysis examines the relationship between vertical integration and some determinants in a market where domestic firms compete. However, the study did not discuss the effects of vertical integration on inputs and outputs markets. Our future research will also consider firms' strategic choice in a different environment where domestic firms compete with overseas firms. We expect the basic results of this paper to hold in these extended settings as well.

\section{Funding}

This research is supported by Japan Society for Promotion of Science, Grant-in-Aid, for grant number 15H03396, 15K03749, and 25380549.

\section{References}

[1] Coase, R.H. (1937) The Nature of the Firm. Economica, 4, 386-405. https://doi.org/10.1111/j.1468-0335.1937.tb00002.x

[2] Williamson, O.E. (1975) Markets and Hierarchies: Analysis and Antitrust Implications: A Study of Internal Organization. The Free Press, New York.

[3] Williamson, O.E. (1985) The Economic Institutional of Capitalism. The Free Press, New York

[4] Grossman, S. and Hart, O. (1986) The Costs of Benefits of Ownership. Journal of Political Economy, 94, 691-719. https://doi.org/10.1086/261404

[5] Hart, O. and Moore, J. (1990) Property Rights and the Nature of the Firms. Journal of Political Economy, 98, 1119-1158. https://doi.org/10.1086/261729

[6] Bonanno, G. and Vickers, J. (1988) Vertical Separation. Journal of Industrial Economics, 36, 257-265. https://doi.org/10.2307/2098466

[7] Chen, Y. (2001) On Vertical Mergers and Their Competitive Effects. Rand Journal of Economics, 32, 667-685. https://doi.org/10.2307/2696387

[8] Lin, P. (2006) Strategic Spin-Offs of Input Divisions. European Economic Review, 50, 977-993. https://doi.org/10.1016/j.euroecorev.2004.12.001

[9] Milgrom, P. (1988) Employment Contracts, Influence Activities and Efficient Organization Design. Journal of Political Economy, 96, 42-60. https://doi.org/10.1086/261523

[10] Milgrom, P. and Roberts, J. (1988) An Economic Approach to Influence Activities in Organizations. American Journal of Sociology, 94, 154-179. https://doi.org/10.1086/228945

[11] Milgrom, P. and Roberts, J. (1992) Economics, Organization and Management. Prentice Hall, Upper New Jersey, NJ. 
[12] Meyer, M.A., Milgrom, P. and Roberts, J. (1992) Organizational Prospects, Influence Costs, and Ownership Changes. Journal of Economics \& Management Strate$g y, 1,9-35$. https://doi.org/10.1111/j.1430-9134.1992.00009.x

[13] Buchler, S. and Schmutzler, A. (2008) Intimidating Competitors-Endogenous Vertical Integration and Downstream Investment in Successive Oligopoly. International Journal of Industrial Organization, 26, 247-265. https://doi.org/10.1016/j.ijindorg.2006.11.005

[14] Bettignies, J.E. (2006) Product Market Competition and Boundaries of the Firm. Canadian Journal of Economics, 39, 948-970. https://doi.org/10.1111/j.1540-5982.2006.00377.x

[15] Rey, P. and Stiglitz, J. (1988) Vertical Restraints and Producers' Competition. European Economic Review, 32, 561-568.

[16] Gal-Or, E. (1999) Vertical Integration and Separation of the Sales Function as Implied by Competitive Forces. International Journal of Industrial Organization, 17, 641-662. https://doi.org/10.1016/S0167-7187(97)00056-8

[17] Salinger, M. (1988) Vertical Mergers and Market Foreclosure. Quarterly Journal of Economics, 103, 345-356. https://doi.org/10.2307/1885117

[18] McBride, M. (1983) Spatial Competition and Vertical Control with Variable Proportions. American Economic Review, 73, 1011-1022.

[19] Hortacsu, A. and Syverson, C. (2007) Cementing Relationships: Vertical Integration, Foreclosure, Productivity, and Prices. Journal of Political Economy, 115, 250-301. https://doi.org/10.1086/514347

[20] Hasbrouck, J. (1985) The Characteristics of Takeover Targets, Q and Other Measures. Journal of Banking and Finance, 9, 351-362. https://doi.org/10.1016/0378-4266(85)90038-X

[21] Andrade, G. and Stafford, E. (2004) Investigating the Economic Role of Mergers. Journal of Corporate Finance, 10, 1-36. https://doi.org/10.1016/S0929-1199(02)00023-8

[22] Danzon, P.M., Epstein, A. and Nicholson, S. (2007) Mergers and Acquisitions in the Pharmaceutical and Biotech Industries. Managerial and Decision Economics, 28, 307-328. https://doi.org/10.1002/mde.1343

[23] Vyas, V., Narayanan K. and Ramanathan A. (2012) Determinants of Mergers and Acquisitions in Indian Pharmaceutical Industry. Eurasian Journal of Business and Economics, 5, 79-102.

[24] Servaes, H. (1991) Tobin's Q and the Gains from Takeovers. Journal of Finance, 46, 409-419. https://doi.org/10.1111/j.1540-6261.1991.tb03758.x

[25] Blonigen, B. and Taylor, C. (2000) R\&D Intensity and Acquisitions in High-Technology Industries: Evidence from the US Electronic and Electrical Equipment Industries. Journal of Industrial Economics, 48, 47-70. https://doi.org/10.1111/1467-6451.00112

[26] Bain, J.S (1956) Barriers to New Competition: Their Character and Consequences in Manufacturing Industries. Harvard University Press, Cambridge, MA.

[27] Comanor, W.S. and Wilson, T.A. (1974) Advertising and Market Power. Harvard University Press, Cambridge, MA.

[28] Vernon, J.M. and Nourse, R.E.M. (1973) Profit Rates and Market Structure of Advertising Intensive Firms. The Journal of Industrial Economics, 22, 1-20. https://doi.org/10.2307/2098181

[29] Porter, M.E. (1976) Inter-Brand Choice, Strategy, and Bilateral Market Power. Harvard University Press, Cambridge, MA. 